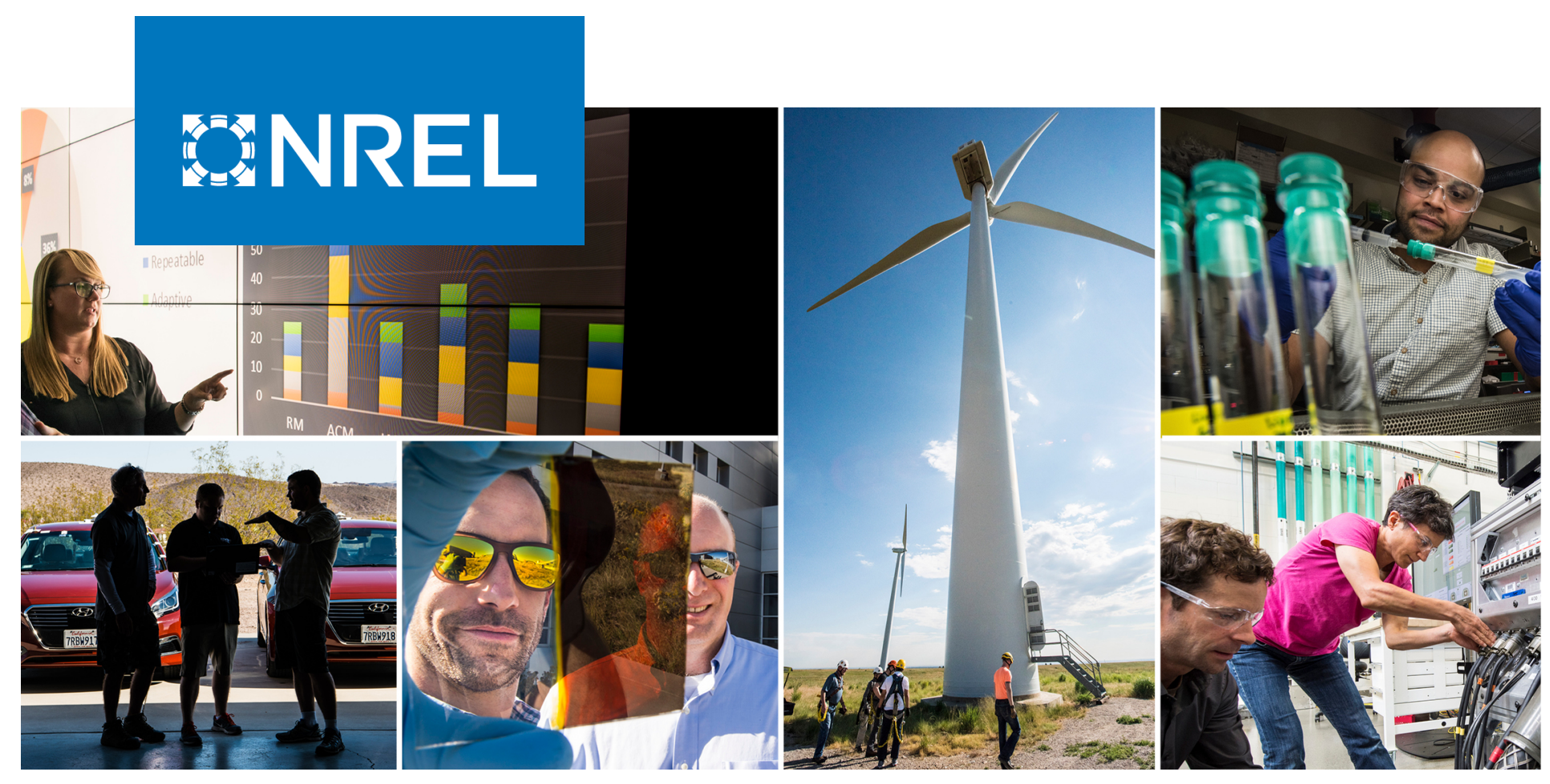

\title{
Distributed Wind Considerations From the IEEE 1547-2018 Revision
}

Robert Preus, ${ }^{1}$ Jim Reilly, ${ }^{1}$ Jay Johnson, ${ }^{2}$ lan Baring-Gould, ${ }^{1}$ and Michael Coddington ${ }^{1}$

1 National Renewable Energy Laboratory

2 Sandia National Laboratories

NREL is a national laboratory of the U.S. Department of Energy Office of Energy Efficiency \& Renewable Energy

Operated by the Alliance for Sustainable Energy, LLC

This report is available at no cost from the National Renewable Energy Laboratory (NREL) at www.nrel.gov/publications.
Technical Report

NREL/TP-7A40-78948

March 2021 


\section{GNREL}

\section{Distributed Wind Considerations From the IEEE 1547-2018 Revision}

Robert Preus, ${ }^{1}$ Jim Reilly, ${ }^{1}$ Jay Johnson, ${ }^{2}$ lan Baring-Gould, ${ }^{1}$ and Michael Coddington ${ }^{1}$

1 National Renewable Energy Laboratory

2 Sandia National Laboratories

\section{Suggested Citation}

Preus, Robert, Jim Reilly, Jay Johnson, lan Baring-Gould, Michael Coddington. 2021.

Distributed Wind Considerations From the IEEE 1547-2018 Revision. Golden, CO:

National Renewable Energy Laboratory. NREL/TP-7A40-78948.

https://www.nrel.gov/docs/fy210sti/78948.pdf.

NREL is a national laboratory of the U.S. Department of Energy Office of Energy Efficiency \& Renewable Energy Operated by the Alliance for Sustainable Energy, LLC

This report is available at no cost from the National Renewable Energy Laboratory (NREL) at www.nrel.gov/publications.

Contract No. DE-AC36-08GO28308
Technical Report NREL/TP-7A40-78948 March 2021

National Renewable Energy Laboratory 15013 Denver West Parkway Golden, CO 80401 303-275-3000 • www.nrel.gov 


\section{NOTICE}

This work was authored [in part] by the National Renewable Energy Laboratory, operated by Alliance for Sustainable Energy, LLC, for the U.S. Department of Energy (DOE) under Contract No. DE-AC36-08GO28308. Funding provided by the U.S. Department of Energy Office of Energy Efficiency and Wind Energy Technologies Office. The views expressed herein do not necessarily represent the views of the DOE or the U.S. Government.

This report is available at no cost from the National Renewable Energy Laboratory (NREL) at www.nrel.gov/publications.

U.S. Department of Energy (DOE) reports produced after 1991 and a growing number of pre-1991 documents are available free via www.OSTI.gov.

Cover Photos by Dennis Schroeder: (clockwise, left to right) NREL 51934, NREL 45897, NREL 42160, NREL 45891, NREL 48097, NREL 46526.

NREL prints on paper that contains recycled content. 


\section{Preface}

The revision of the U.S. interconnection standard Institute of Electrical and Electronics Engineering (IEEE) 1547 in 2018 (IEEE 1547-2018) has added new interconnection and interoperability requirements for grid-connected distributed wind generators and all other distributed energy resources (DERs). These new requirements will enable distributed wind generators to provide greater benefits to electric grid and DER operators, but also presents new challenges for the testing and certification of distributed wind generator systems. This report provides a summary of recent interconnection standard revisions from a distributed wind generator perspective, outlines the potential benefits to the power system from the revisions, evaluates the main concerns from a distributed wind generator manufacturer's perspective, and provides general industry guidance related to IEEE 1547-2018 adoption. Specifically, this report provides insight and guidance on several concerns and considerations that have been identified around distributed wind generator compliance with IEEE 1547-2018, IEEE 1547.1 certification standard (expected in 2020), and ANSI-approved test procedures in Underwriters Laboratories (UL) 1741 Supplement $B^{1}$ (anticipated in 2021). At this time, DER inverters are being listed to UL 1741 SA (UL 2016), which covers the grid-support requirements developed by Hawaii and California.

${ }^{1} \mathrm{UL} 1741$ is the equipment standard for distribution-connected DERs including distributed wind generators and is harmonized with IEEE 1547 and IEEE 1547.1. See "Underwriters Laboratories 1741 Ed. 2," Inverters Converters Controllers and Interconnection System Equipment for use with Distributed Energy Resources, 2010. 


\section{Table of Contents}

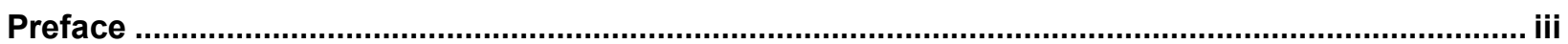

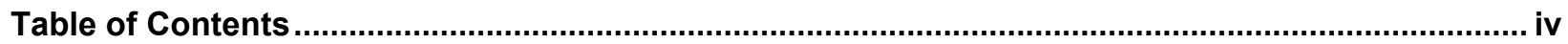

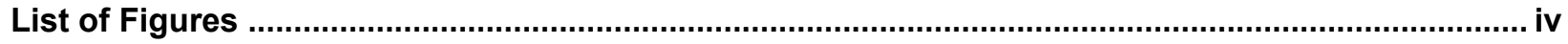

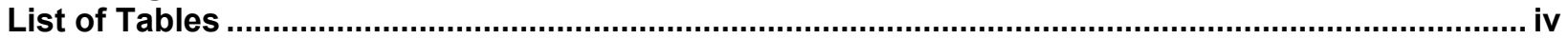

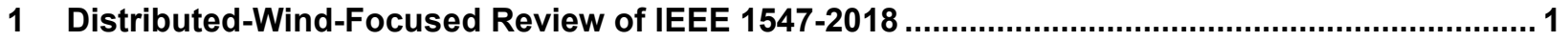

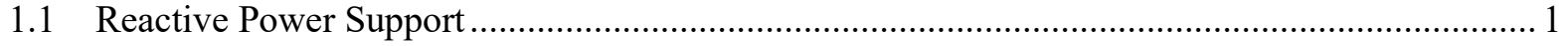

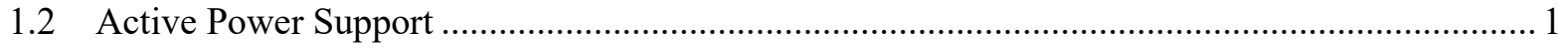

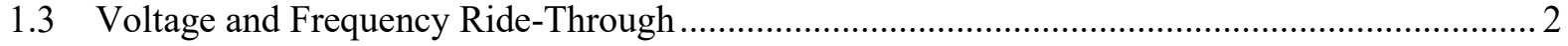

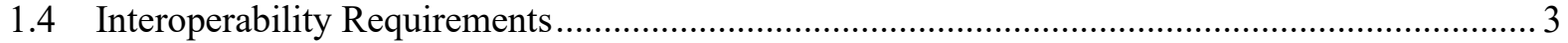

2 Benefits of IEEE 1547-2018 to the Power System .................................................................... 5

2.1 Isolated Grid Systems and Microgrids in Island Mode ....................................................... 5

3 Impact to Software Implementation and Wind Turbine System Certification .............................. 6

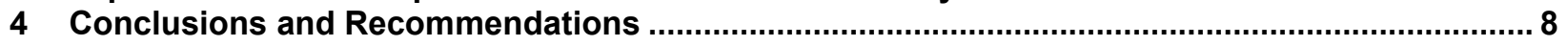

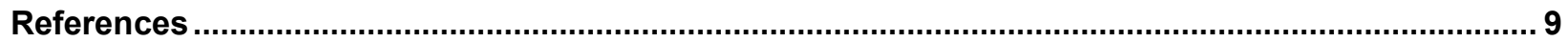

\section{List of Figures}

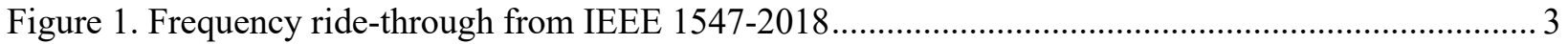

Figure 2. Voltage ride-through regions from IEEE 1547-2018 ….................................................... 3

\section{List of Tables}

Table 1. Distributed Wind Turbine Models With Inverters. 


\section{Distributed-Wind-Focused Review of IEEE 1547-2018}

IEEE 1547-2018 requires all DERs to be capable of providing multiple grid-support functions as well as advanced communications and control functionality. IEEE 1547-2018 has additional requirements in the areas of reactive power controls, active power controls, and voltage and frequency ride-through capabilities (including must-stay-connected regions and must-trip regions). IEEE 1547-2003 had no requirements for DERs to remain connected during any voltage or frequency aberrations and was considered a "low penetration interconnection standard." The North American Electric Reliability Corporation and electric utilities have been vocal advocates of having DERs, including distributed wind, behave in a similar manner as the larger bulk power system generators. Therefore, many of the new requirements for distributed wind generators have created a new set of challenges and demands for distributed wind system developers as they must create next-generation hardware, software, and testing tools.

\subsection{Reactive Power Support}

Under IEEE 1547-2018, all DERs are required to have multiple reactive power control function capabilities, including:

- A constant power factor mode

- A voltage-reactive power (volt-var) mode

- An active power-reactive power (watt-var or P-Q) mode

- A constant reactive power mode.

These capabilities are designed to provide options for distribution system voltage support. In the case of the volt-var control function, the DER is programmed to absorb reactive power during higher voltage conditions and to inject reactive power during lower voltage conditions. This reactive power control approach provides a means to autonomously control localized voltage levels without regular utility communications to the DER equipment. DERs that export power to the distribution systems place upward pressure on voltage levels on a distribution circuit (e.g., feeders, branch circuits, and lowvoltage secondary wires), which makes a local autonomous response to maintain proper voltage levels critical for most consumer and utility equipment. The reactive power support mode can be fixed in the interconnection contract or be subject to change in response to communication from the utility or an aggregator.

\subsection{Active Power Support}

DERs are required to adjust their active power output under the new requirements in IEEE 1547-2018, utilizing a number of new functions that include:

- Disable permit service

- Limit active power

- Frequency droop (frequency-power)

- Voltage-active power (volt-watt) mode.

In the case of distributed wind generation systems, limiting active power will act as a curtailment function to reduce the active power export of the distributed wind generators. These functions are designed to support bulk power system balancing. The frequency-droop functionality is intended to 
replicate generator frequency-droop governor systems in which the DERs autonomously respond to changes in grid frequency with adjustments in active power, thereby reducing active power with higher frequency and increasing power, if available, during lower-frequency situations. In the extreme case, volt-watt is used to limit overvoltage excursions. In Hawaii, it has been shown that the combination of volt-var and volt-watt could allow the acceptance of solar photovoltaic (PV) installations on residential feeders to go from a limit of $100 \%$ of daytime minimum load to $250 \%$. The impact on active power production as a result of curtailment is small (Hoke 2019). The disable permit service and limit active power functions would normally be used though a communications interface to provide short-term benefits (e.g., reduction in overgeneration).

\subsection{Voltage and Frequency Ride-Through}

IEEE 1547-2003 required distributed resources to trip offline if a grid disturbance resulted in the voltage or frequency to be out of a fairly narrow operating range and remain disconnected for at least 5 minutes after the grid was stable. The standard did not require DERs to ride-through grid perturbations, a gap which has now been addressed in the 2018 standard.

IEEE 1547-2018 requires all types of DERs to have the capability to ride-through both voltage and frequency aberrations and stay connected while providing energy to the grid. The required limits vary, depending on class and category of DER. For example, a diesel generator has more limited voltage ridethrough ranges than an inverter based DER such as distributed wind or PV.

For voltage and frequency "abnormal condition" events, there are default settings and clearing times for tripping, with a range of adjustment capabilities required (and that vary depending on type of technology). Depending on the power system needs, the area electric power system operator may adjust the ride-through ranges for the DER anywhere within the ranges of adjustment of the equipment required by the IEEE 1547-2018 standard. Within the various envelopes of operations (both frequency and voltage), there are regions of mandatory operation, permissive operation, and must-trip regions. See Figure 1 and Figure 2 for a representation of the frequency ride-through and voltage ride-through operational regions. 


\section{Frequency Ride-Through}

(Default Values for All Categories)

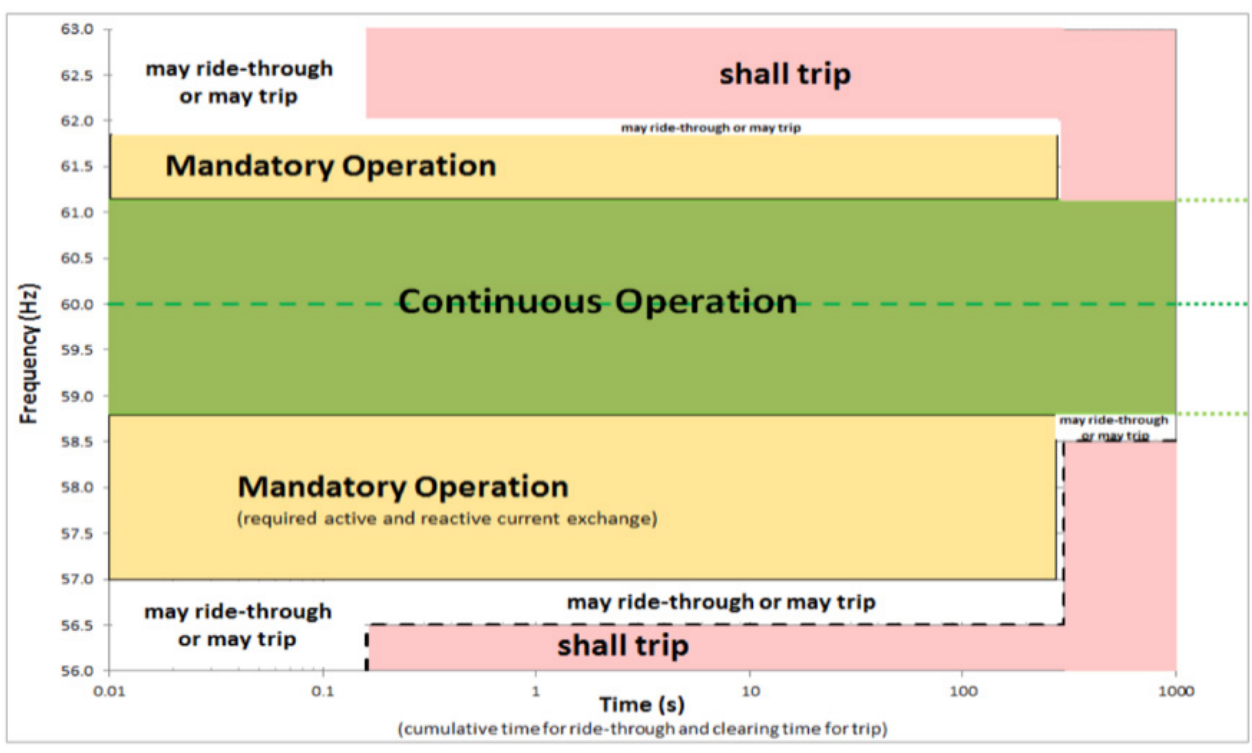

Figure 1. Frequency ride-through from IEEE 1547-2018

\section{Voltage Ride-Through (All Categories)}

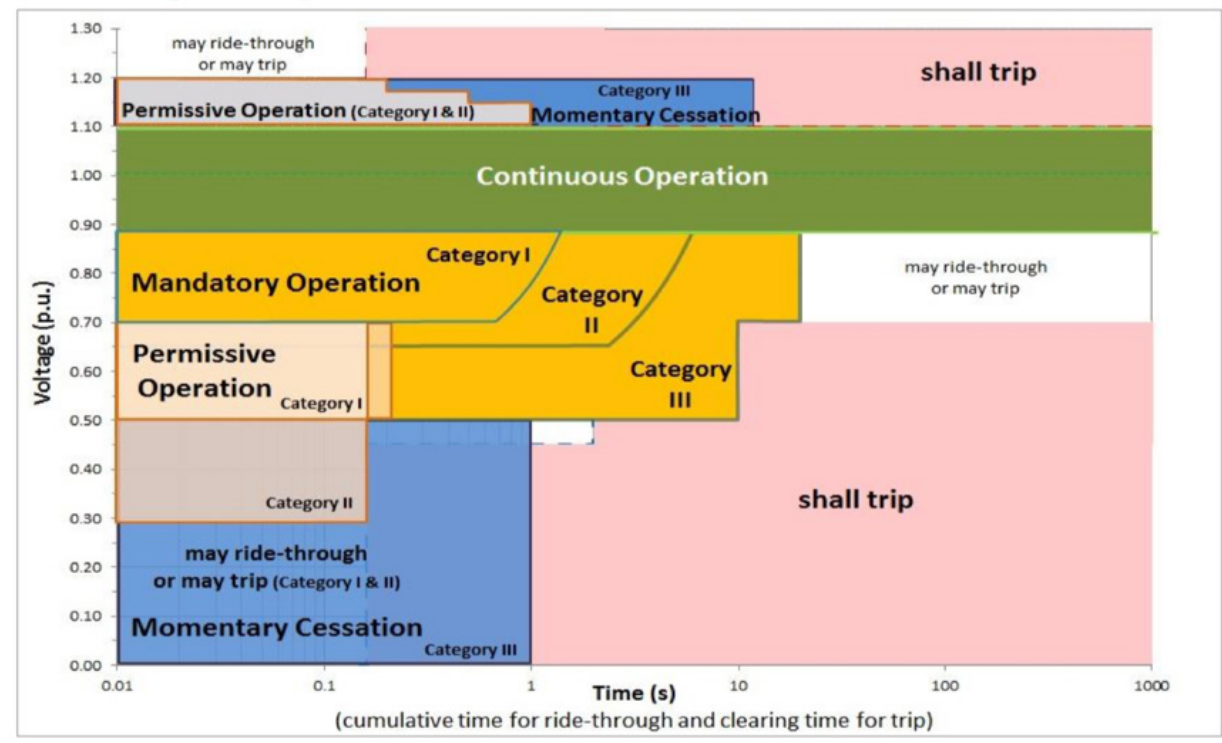

Figure 2. Voltage ride-through regions from IEEE 1547-2018

\subsection{Interoperability Requirements}

IEEE 1547-2018 requires DER equipment to have one standardized communication interface compliant to either IEEE 1815, IEEE 2030.5, or SunSpec Modbus. These interfaces must be able to receive and activate changes of the adjustable parameters for active power, reactive power, and ride-through modes. This is a major change to the required DER functionality, compared to IEEE 1547-2003, which has no 
communications, and it will enable grid operators with powerful new control capabilities as the numbers of DERs increase. For systems with many small DER installations, the electric power system operator may require an aggregator to provide the functional communications to individual DER installations. An aggregator contracts with many DERs and provides one point of contact for the utility. They manage communications, control, and payment. 


\section{Benefits of IEEE 1547-2018 to the Power System}

The functionality defined in IEEE 1547-2018 provides grid operators new capabilities to adjust and monitor the power system. The interoperability functionality provides a means to monitor the power system and control DERs to support and optimize distribution and bulk-system operations. However, monitoring and modifying DER parameters on a fleet of millions of DERs may be daunting to some grid operators, so many are looking to DER vendors and aggregators to manage these fleets. Some inverters companies, for example, have the capability to monitor and modify the behavior of millions of devices ${ }^{2}$ from their control center (coordinated with the area electric power system operator). This may become a more prevalent method of operating fleets of DERs including distributed wind generators. Additionally, it is likely that bandwidth and latency challenges with DER communications will encourage utilities and aggregators to use autonomous functions, such as volt-var and volt-watt, versus commanded functions like constant reactive power or limit active power modes, to ensure long-term stable grid operations.

Distribution networks have carefully coordinated the voltage profile along feeders. Many utilities and power system operators were hesitant to allow large contributions of wind and solar PV on distribution feeders because these devices impact the voltage profile. The reactive power control modes in IEEE 1547-2018 will permit higher hosting capacities on distribution circuits.

\subsection{Isolated Grid Systems and Microgrids in Island Mode}

The new functionality in IEEE 1547-2018 is also well-suited for isolated grids such as island systems (e.g., Hawaii and Puerto Rico) or microgrid systems ${ }^{3}$ Because isolated grid systems cannot rely on support of neighboring balancing authorities, DERs in these regions must be capable of riding through grid disturbances and providing grid operators with tools to balance load and generation. Wide ridethrough ranges are especially helpful for smaller grid systems, as frequency and voltage swings are greater than on larger grid systems.

Development of a microgrid is currently considered a custom engineering job that requires the selection or even the development of components that could provide the required communications, voltage, and frequency support functions. Now, all required communications and grid support functions will be available in off-the-shelf inverters, including distributed wind generators, PV inverters, and storage inverters. These devices are required to have adjustable set points that will allow them to easily adjust for operation with the microgrid controller. This, along with advancing load management and control, will simplify development of microgrid systems.

\footnotetext{
${ }^{2}$ For example, see the HECO and Enphase story in IEEE Spectrum here. 


\section{Impact to Software Implementation and Wind Turbine System Certification}

For type 3 and 4 wind turbines that are largely connected to the grid through back-to-back inverters, the availability of inverters was already a problem before IEEE 1547-2018. The first and largest supplier for inverters for small wind was SMA, which provided a version of their SunnyBoy inverter aptly named the WindyBoy. It was discontinued at the end of 2013. Small wind original equipment manufacturers switched to the Aurora Power One inverter line that was available in a configuration for wind generators. That inverter was also discontinued for wind in about 2015. There was advance notice, so companies stocked up and carried on for some time with the Power One. The only inverter left on the open market that was listed for wind was the Ginlong and they dropped the wind version of their inverter in about 2018. Bergey WindPower had their own inverter that they received by purchasing a small inverter company that was their supplier. New small wind original equipment manufacturers have been using inverters that are listed for any DC source often without support from the manufacturer for application with a wind generator. Intergrid has developed a 25-kilowatt inverter specifically for wind applications and a wind generator interface for their inverter; however, it is not yet listed and in production. The development of the Intergrid inverter was supported by the U.S. Department of Energy through the Competitiveness Improvement Project administered by the National Renewable Energy Laboratory. However, the challenge of getting inverters listed and into production is significantly steeper with IEEE 1547-2018.

Although meeting the new IEEE 1547 requirements typically does not require a major change in the power stage and power electronics hardware of an inverter, it does require additional engineering and testing that will significantly increase the cost of product development. DER vendors will also need to upgrade the processors, onboard storage, and communication modules. For distributed wind generators, sourcing an inverter was already a significant barrier if they could not utilize high-volume solutions from other markets. Wind turbine control software is a critical component of any distributed wind generation system, and development costs are likely the most challenging issue in meeting IEEE 15472018 because of the increased complexity of the controls required to meet the standard. The financial impacts to wind turbine or inverter manufacturers will primarily be in engineering/design work and the time, labor, and fees paid to a certification body (typically a Nationally Recognized Testing Laboratory).

The new IEEE 1547.1 certification standard includes a suite of tests to validate the electrical and interoperability functionality of DER equipment. Each of the operating modes are tested at different parameters to ensure correct operation over the range of adjustability of the functions. This is a major challenge to the DER industry and Nationally Recognized Testing Laboratories because the tests are more expensive and take longer to perform than testing for the original IEEE 1547-2003. Wind generator certification testing over the range of operating limits and adjustments to the software of inverters will likely increase testing costs, perhaps by $200 \%-400 \%$ (based on UL experience). Intertek is quoting 6 weeks of testing.

Because California and Hawaii already require the advanced inverter functions and other states will soon, all distributed wind original equipment manufacturers either meet or more often are in the process of meeting the standard.

There are 16 distributed wind turbines listed in Table 1, with information on their rating, type, and inverter capability, if available. Half of the manufacturers have either not selected an inverter supplier (because they are early in the design process) or have not disclosed that information. Three 
manufacturers are using solar inverters or regenerative drives. These solar inverters and regenerative drives do not appear to have grid support capability. Semtive is working on getting an inverter listed to UL1741SA. Three manufacturers are planning on using Intergrid inverters that have UL1741SA capability but are not yet listed. Star Wind has paid Growatt to add a wind application to their inverter, which is listed to UL1741SA. Pecos is working with Windurance, a pitch drive manufacturer, to develop an inverter to UL1741SA.

Table 1. Distributed Wind Turbine Models With Inverters

\begin{tabular}{|c|c|c|c|c|c|c|c|}
\hline Company & $\begin{array}{l}\text { Product } \\
\text { Name }\end{array}$ & Type & $\begin{array}{l}\text { Nominal } \\
\text { Power } \\
\text { (kilowatts) }\end{array}$ & $\begin{array}{l}\text { Production } \\
\text { Status }\end{array}$ & $\begin{array}{l}\text { Rotor } \\
\text { Diameter } \\
\text { (meters) }\end{array}$ & $\begin{array}{l}\text { Electrical } \\
\text { Output }\end{array}$ & Inverter \\
\hline Semtive & Nemoi M & $\begin{array}{l}\text { Vertical- } \\
\text { axis wind } \\
\text { turbine } \\
\text { (VAWT) }\end{array}$ & 2.4 & Production & 3 by 3 & $\begin{array}{l}110 / 220 \text { (volts } \\
\text { AC) VAC }\end{array}$ & $\begin{array}{l}\text { Working on UL1741SA } \\
\text { listing }\end{array}$ \\
\hline Sonsight & & $\begin{array}{l}\text { Horizontal } \\
\text {-axis wind } \\
\text { turbine } \\
\text { (HAWT) }\end{array}$ & 3.5 & Prototype & 5 & $240 \mathrm{VAC}, 1 \phi$ & ABB solar not $1547 \mathrm{SA}$ \\
\hline Ducted & & HAWT & 3.5 & Development & 3.7 & & not selected yet \\
\hline Uprise & & HAWT & 10 & Production & 6.6 & & not disclosed \\
\hline Bergey & Excel 15 & HAWT & 15 & Production & 9.6 & $\begin{array}{l}240 \mathrm{~V}, 1 \phi \\
240 \mathrm{~V}, 3 \phi\end{array}$ & $\begin{array}{l}\text { Intergrid } \\
\text { UL1741 SA designed } \\
\text { Not listed }\end{array}$ \\
\hline Chava & $\begin{array}{l}\text { Windleaf } \\
2500\end{array}$ & VAWT & 20 & Prototype & 9.6 by 14.2 & $\begin{array}{l}240 \mathrm{~V}, 1 \phi \\
240 \mathrm{~V}, 3 \phi\end{array}$ & $\begin{array}{l}\text { Intergrid } \\
\text { UL1741 SA designed } \\
\text { Not listed }\end{array}$ \\
\hline QED & & HAWT & 20 & Production & 12.5 & & $\begin{array}{l}\text { Intergrid UL1741 SA } \\
\text { designed } \\
\text { Not listed }\end{array}$ \\
\hline Eocycle & EO-25 & HAWT & 25 & Production & 15.8 & 480 VAC, $3 \phi$ & ABB ACS800-11 \\
\hline xFlow & & VAWT & 25 & Pre-prototype & & & Not selected yet \\
\hline Star Wind & Star 72-6 & HAWT & 45 & $\begin{array}{l}\text { Prototype } \\
\text { testing }\end{array}$ & 22 & 480 VAC, $3 \phi$ & Growatt UL1741SA \\
\hline Windward & & HAWT & 50 & Preprototype & 23 & 480 VAC, $3 \phi$ & Yes, not selected \\
\hline Pecos & & HAWT & 85 & $\begin{array}{l}\text { Prototype } \\
\text { designed }\end{array}$ & 30 & 480 VAC, $3 \phi$ & Windurance \\
\hline XANT & $M-24$ & HAWT & 95 & Production & 24 & $480 \mathrm{VAC}, 3 \phi$ & $\begin{array}{l}\text { Yes, no info at this } \\
\text { time }\end{array}$ \\
\hline $\begin{array}{l}\text { Heartland } \\
\text { Energy }\end{array}$ & Freedom 100 & HAWT & 100 & Production & 27.3 & 480 VAC, $3 \phi$ & $\begin{array}{l}\text { Yes, no info at this } \\
\text { time }\end{array}$ \\
\hline Carter & Model 300 & HAWT & 275 & $\begin{array}{l}\text { Starting } \\
\text { production }\end{array}$ & 30.5 & $480 \mathrm{VAC}, 3 \phi$ & $\begin{array}{l}\text { Yes, no info at this } \\
\text { time }\end{array}$ \\
\hline Carter & Model 500 & HAWT & 395 & Development & 36.6 & 480 VAC, $3 \phi$ & $\begin{array}{l}\text { Yes, no info at this } \\
\text { time }\end{array}$ \\
\hline
\end{tabular}




\section{Conclusions and Recommendations}

The distributed wind industry is now required to add new electrical and interoperability functionality to distributed wind generator. As a result, several proactive steps can be taken by distributed wind manufacturers to minimize the impact and costs to the industry:

1. Incorporate technologies from PV inverter manufacturers, who have developed these gridsupport functions over the last decade for the U.S., European, and Asian markets. The solar industry has incorporated many of the IEEE 1547-2018 functions in their inverter technologies for more than a decade to meet the requirements in different countries. Working with these manufacturers would streamline the process of becoming compliant with IEEE 1547-2018. In some cases, directly interfacing solar inverter control mechanisms into distributed wind generation products could be possible.

2. Leverage existing communication modules from third-party companies. There are multiple companies providing IEEE 1815, IEEE 2030.5, and SunSpec Modbus communication components that could be interfaced with the distributed wind generation controller. As a result, these products would act as the standardized communication interfaces for the device and relay commands to the power stage controller.

3. Adopt controller hardware-in-the-loop technologies during development. Recent advances in this type of technology allows for faster design iterations of electrical controls and communications componentry. By connecting the communications module and the DER controller to a virtualized power stage, the new controls and communications capabilities can be validated without risk to the power stage, by using a small form factor, and at low current and voltage levels (Johnson et al. 2018b; Johnson et al. 2017).

4. Automated validation and certification of DER grid-support functionality. For more than 5 years, a community of laboratories has been working on a common test platform for validating the functionality of DER devices to a range of interconnection standards. This open-source SunSpec System Validation Platform (SVP) interfaces with DC power supplies, grid simulators, data acquisition systems, and the equipment under test to automate compliance testing. Currently, several IEEE 1547.1 test scripts have been developed and are free to the DWG community to use for validation of their equipment prior to-or during - NRTL certification (Ninad et al. 2019; Johnson et al. 2018a; System Validation Platform; IEEE Test Scripts. 


\section{References}

Hoke, A. 2019. “Smart Inverter Utility Experience in Hawaii.” IEEE PES General Meeting Tutorial on Smart Inverters for Distributed Generators, Atlanta, Georgia, August 4, 2019. Golden, CO: National Renewable Energy Laboratory (NREL). NREL/PR-5D00-74091. https://www.nrel.gov/docs/fy19osti/74091.pdf.

Institute of Electrical and Electronics Engineers (IEEE). 2018. IEEE Standard for Interconnection and Interoperability of Distributed Energy Resources with Associated Electric Power Systems Interfaces. IEEE Std 1547-2018 (Revision of IEEE Std 1547-2003).

IEEE. 2021. "IEEE 1547.1 Test Scripts.” Accessed March 26, 2020. https://github.com/jayatsandia/svp_1547.1.

Johnson, J., R. Ablinger, R. Bruendlinger, B. Fox, J. Flicker. 2017. "Design and Evaluation of SunSpecCompliant Smart Grid Controller with an Automated Hardware-in-the-Loop Testbed." Technology and Economics of Smart Grids and Sustainable Energy, vol. 2, no. 16. doi: 10.1007/s40866-017-0032-7.

Johnson, J., E. Apablaza-Arancibia, N. Ninad, D. Turcotte, A. Prieur, R. Ablinger, R. Brïndlinger, T. Moore, R. Heidari, J. Hashimoto, C. Cho, R. S. Kumar, J. Kumar, et al. 2018a. "International Development of a Distributed Energy Resource Test Platform for Electrical and Interoperability Certification." 7th World Conference on Photovoltaic Energy Conversion (WCPEC-7), Waikoloa, Hawaii, June 10-15, 2018. https://ieeexplore.ieee.org/stamp/stamp.jsp?arnumber=8547588.

Johnson, J., R. Ablinger, R. Bruendlinger, B. Fox, J. Flicker. 2018b. "Interconnection Standard GridSupport Function Evaluations using an Automated Hardware-in-the-Loop Testbed." IEEE Journal of Photovoltaics, vol. 8, no. 2, pp. 565-571. doi: 10.1109/JPHOTOV.2018.2794884.

Ninad, N., E. Apablaza, M. Bui, J. Johnson, S. Gonzalez, W. Son, C. Cho, J. Hashimoto, K. Otani, et al. 2019. "Development and Evaluation of Open-Source IEEE 1547.1 Test Scripts for Improved Solar Integration.” EU PVSEC, Marseille, France, September 9-13, 2019.

System Validation Platform. Accessed March 26-20, 2020. https://github.com/sunspec/svp.

Underwriters Laboratories (UL). 2016. UL 1741 Supplement SA: Grid Support Utility Interactive Inverters and Converters. 